\title{
Evaluation of the Quality of Videos on Hemorrhoidal Disease on YouTube ${ }^{\mathrm{TM}}$
}

\section{Youtube $^{\mathrm{TM}}$ 'da Hemoroidal Hastalık ile Illgili Videoların Kalitesinin Değerlendirilmesi}

\author{
(1) Veysel Barış Turhan, () Abdülkadir Ünsal \\ Keçiören Training and Research Hospital, Clinic of General Surgery, Ankara, Turkey
}

\section{HIIIII| ABSTRACT}

\begin{abstract}
Aim: Patients frequently use YouTube ${ }^{\mathrm{TM}}$ as a platform for obtaining information. Hemorrhoidal disease is considered as one of the common diseases in the general population. Currently, there exists no study evaluating the quality of YouTube ${ }^{\mathrm{TM}}$ videos regarding hemorrhoids. Our study aims to investigate the quality of videos on hemorrhoids on YouTube ${ }^{\mathrm{TM}}$.

Method: The term "Hemorrhoids" was searched on the YouTube ${ }^{\mathrm{TM}}$ portal on December 13, 2020. The 68 most clicked videos were analyzed in the study. Video durations; the number of clicks, likes, dislikes, comments; and published dates were noted. In addition, video uploaders and video contents were examined. The Video Power Index (VPI) was calculated. Video quality was evaluated using the DISCERN, JAMA, GQS, and modified DISCERN scoring systems.

Results: The average number of clicks on videos was $711,051,41$. The daily view count was $603.63 \pm 1240.2$. The average length of the videos was $327.69 \pm 324.17$ s. The most common video uploaders were doctors [39 (57.3\%)]. The average DISCERN, JAWA, GQB, modified DISCERN scores were low. Video length, daily clicks, VPI, and comments/year did not affect these scores. According to the groups, all quality values were better in the videos uploaded by the physicians. In addition, the groups with more than 200 views/day had statistically better GQS.

Conclusion: The quality of videos regarding hemorrhoids on YouTube ${ }^{\mathrm{TM}}$ was insufficient. Of all uploaded videos, those uploaded by the doctors were of high quality.
\end{abstract}

Keywords: YouTube ${ }^{\mathrm{TM}}$, hemorrhoid, quality, DISCERN, JAMA, GQS

\section{|IIIIIII| ÖZ}

Amaç: YouTube ${ }^{\mathrm{TM}}$, hastaların bilgi edinmesi için sıklıkla kullanılan bir platformdur. Hemoroidal hastalık, genel popülasyondaki yaygın hastalıklardan biri olarak kabul edilir. Literatürde hemoroidler için YouTube ${ }^{\mathrm{TM}}$ video kalitesini değerlendiren objektif bir çalışma yoktur. Bu çalışmamızda YouTube ${ }^{\mathrm{TM}}$ 'da hemoroidle ilgili videoların kalitesini incelemeyi amaçlamaktadır.

Yöntem: "Hemoroid" 13.12.2020 tarihinde YouTube tarama portalında tarandı. Araştırmaya en çok tıklanan 68 video dahil edildi. Videoların süresi, tıklama sayısı, beğenme, beğenmeme, yorum sayısı, yayınlanma tarihi ve videoların süresi not edildi. Video yükleyiciler, video içeriği incelendi. Video Güç İndeksi (VPI) hesaplandı. Video kalitesi DISCERN, JAMA, GQS ve değiştirilmiş DISCERN puanlama sistemleri ile değerlendirildi.

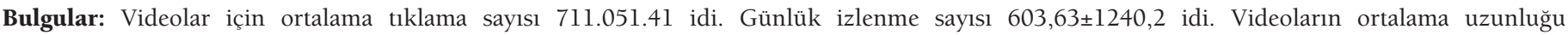
$327,69 \pm 324,17$ saniyeydi. Video yükleyicileri genellikle doktorlardı [39 $(\% 57,3)$ ]. Ortalama DISCERN, JAWA, GQB, modifiye DISCERN puanları düşüktü. Araştırmamız sonucunda video uzunluğu, günlük tıklamalar, VPI ve yorumlar/yıl video kalite puanlarını etkilememişti. Gruplara göre değerlendirmede hekimler tarafından yüklenen videolarda tüm kalite değerlerinin daha iyi olduğu görüldü. Ayrıca, günde 200'den fazla izlenen gruplar istatistiksel olarak daha iyi GQS'ye sahipti.

Sonuç: YouTube ${ }^{\mathrm{TM}}$ video portalında videoların hemoroid video kalitesi yetersizdi. Doktorlar tarafından yüklenen videolar yüksek kalitedeydi. Anahtar Kelimeler: YouTube ${ }^{\mathrm{TM}}$, hemoroid, kalite, DISCERN, JAMA, GQS 


\section{Introduction}

Globally, $63.2 \%$ of the population has access to the Internet. While the highest proportion of population with this access is in North America (90.3\%), only $47.1 \%$ of people in Africa can access the Internet. ${ }^{1}$ YouTube ${ }^{\mathrm{TM}}$ is a video publishing platform that is easily accessible to everyone. It garners approximately 2.1 billion views daily and is viewed by an average of 30 million people daily. ${ }^{2}$ It is inevitable for people to use such a popular website for health-related searches and as a source of information.

Hemorrhoids occur in $14.4 \%-38.9 \%$ of general adult population. ${ }^{3,4}$ According to Google trends, hemorrhoids have been a popular Internet search since 2004. This condition has also been popularly searched on YouTube ${ }^{\mathrm{TM}}$ since 2008. ${ }^{5}$ This is because people are reluctant to go to a doctor when they have an anorectal disease and instead prefer to research on the subject online rather than consulting an expert. Unfortunately, the quality of information regarding hemorrhoid treatment on the Internet can vary widely, and half of the websites on this topic are of poor quality. ${ }^{6}$ Thus, we aimed to investigate the current quality of hemorrhoids, which people hesitate to consult doctors and view as a taboo, on the popular video platform YouTube ${ }^{\mathrm{TM}}$. Although patients are currently using YouTube ${ }^{\mathrm{TM}}$ for obtaining information, many studies have shown that the videos on YouTube ${ }^{\mathrm{TM}}$ are inappropriate and can be misleading. ${ }^{7,8}$

This study aimed to assess the quality of the educational and informative videos related to hemorrhoids on YouTube ${ }^{\mathrm{TM}}$ and their potential contributions to the viewers, using commonly used scoring systems. To the best of our knowledge, this is the first study in the literature to investigate this aspect using four different scoring systems.

\section{Materials and Methods}

The data used in this study were obtained from YouTube ${ }^{\mathrm{TM}}$ videos that are accessible to everyone and open to the public. The study was initiated by inspiring from the systematic examinations of similar studies. ${ }^{9,10,11}$ The term "hemorrhoids" was searched using the YouTube ${ }^{\mathrm{TM}}$ search bar on December 13, 2020, and the results were ranked according to the number of views. Videos with over 100,000 views were included in the study. Duplicate videos, nonEnglish videos, non-hemorrhoid-related videos, videos less than $1 \mathrm{~min}$, and videos containing advertisements were excluded. A total of 68 videos with more than 100,000 views and those meeting the criteria were included.

Two independent general surgery examiners examined and analyzed all videos for their relevance to hemorrhoids and for the information they conveyed. The relationship between the two commentators was evaluated. Descriptive attributes of each video (upload date, number of views, likes, dislikes, and comments under the video) were recorded.

According to the DISCERN, JAMA, global quality score (GQS), and modified DISCERN scores, the quality of education in each video was evaluated. The DISCERN scoring system consists of 16 questions, in 2 parts. ${ }^{12}$ The first eight questions are about reliability, and the next seven questions are regarding the quality of treatment choices (Table 1). The final question is a general assessment question. DISCERN scores are interpreted as follows: 16-26 indicates poor quality, 27-38 indicates low quality, 39-50 indicates average quality, 51-62 indicates good quality, and 6-75 indicates excellent quality. ${ }^{13}$

Video quality was also evaluated using the GQS. The GQS is a 5-point scale used to evaluate the overall quality of videos watched (Table 2).

Subsequently, the data were evaluated using the JAMA scoring system, which is used to assess the quality of healthrelated information available from websites (Table 3). It consists of four criteria: disclosure, currency, attribution, and authorship. Each item is scored as 0 or 1 . A maximum of 4 and a minimum of 0 points are scored on this scale. A high score on this scale indicated that the information was of good quality. ${ }^{8}$

Singh et al. simplified the original DISCERN score, modified it, and defined it as the "modified DISCERN score". ${ }^{14}$ This modified score (Table 4) evaluates credibility, clarity, bias, referencing, and uncertainty of information in YouTube ${ }^{\mathrm{TM}}$ videos. $^{8}$

The Video Power Index (VPI) is used to assess the popularity of a video. ${ }^{15}$ VPI scores were calculated using the following formula: (like count/dislike count + number of likes) X 100 . Thus, the VPIs of all videos were calculated. To avoid bias owing to a video's duration on YouTube ${ }^{\mathrm{TM}}$, the video view ratio was calculated based on total views/time since upload. Video content was grouped according to uploader (physicians/non-physicians), video length $(<5,5-10,>10$ $\mathrm{min}$ ), release date $[<5$ years (new videos) and $>5$ years (old videos)], view count first 34 videos and second 34 videos, daily view count $(<200$ or $>200)$, VPI $(<95$ or $>95)$, and comments/year $(>50$ and $<50)$. The relationship between each group and video quality was evaluated.

Ethics committee approval was not required in this study.

\section{Results}

Of the 100 videos watched, 32 did not meet the inclusion criteria. Of all videos with over 100,000 views, 68 were included in our research. There were 48,351,496 views in total. The average video length was $327.69 \mathrm{~s}$ (standard deviation, $324 \mathrm{~s}$ ). The minimum was length was $73 \mathrm{~s}$, and 
Table 1. Discern scoring system

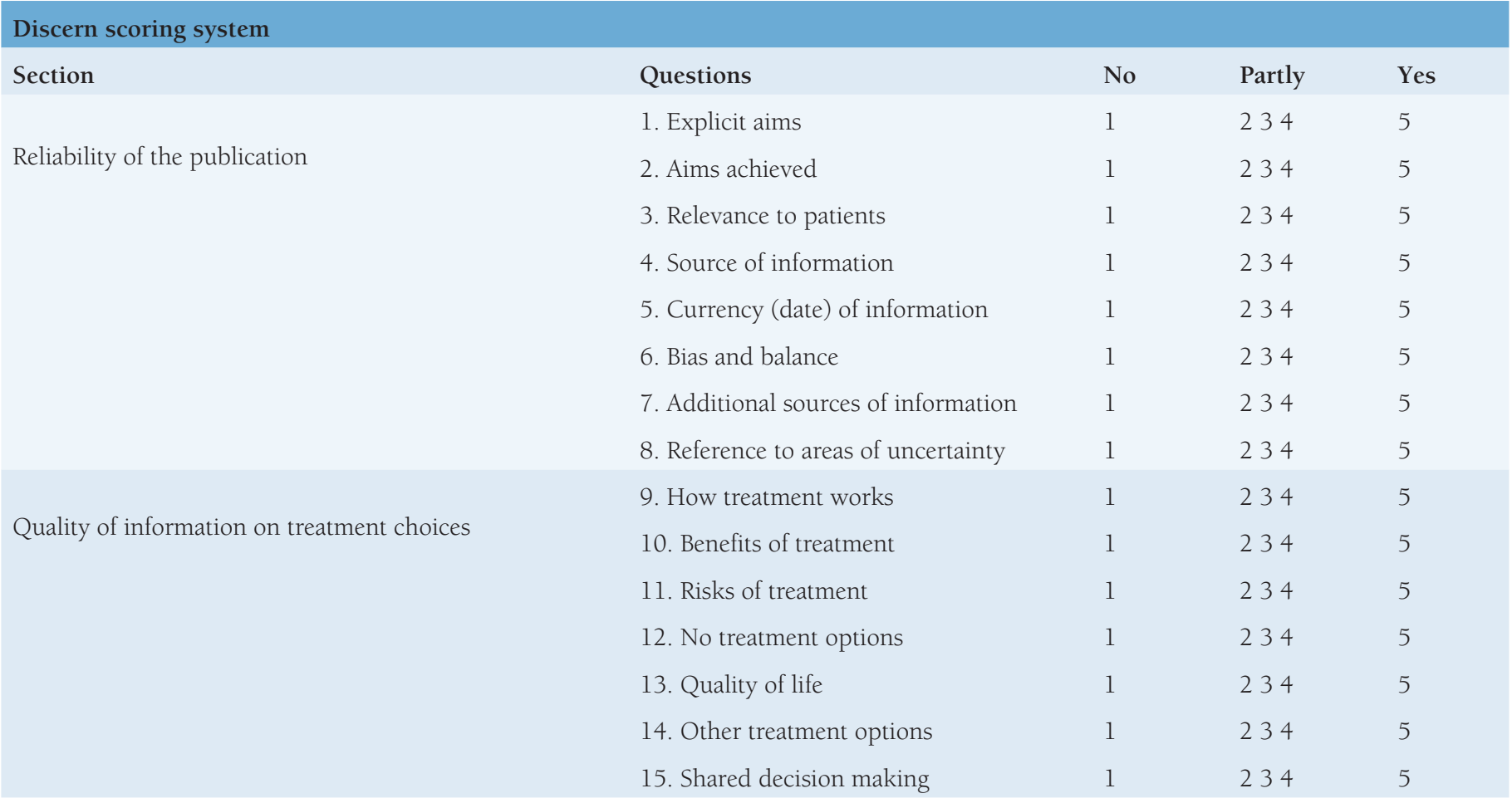

16. Based on the answers to all of these questions, rate the overall quality of the publication as a source of information about treatment choices 12345

Table 2. Global quality scoring

GQS

\section{Score Global score description}

1 Poor quality, poor flow of the site, most information missing, not at all useful for patients

2 Generally poor quality and poor flow, some information listed but many important topics missing, of very limited use to patients

3 Moderate quality, suboptimal flow, some important information is adequately discussed but others poorly discussed, somewhat useful for patients

4 Good quality and generally good flow, most of the relevant information is listed, but some topics not covered, useful for patients

$5 \quad$ Excellent quality and excellent flow, very useful for patients

GQS: Global quality score

Table 3. JAMA scoring system

Jama scoring system

Authorship Authors and contributors, their affiliations, and relevant credentials should be provided

Attribution References and sources for all content should be listed clearly, and all relevant copyright information should be noted

Disclosure Website "ownership" should be prominently and fully disclosed, as should any sponsorship, advertising, underwriting, commercial funding arrangements or support, or potential conflicts of interest

Currency Dates when content was posted and updated should be indicated

JAMA: Journal of the American Medical Association 
the maximum length was $2353 \mathrm{~s}$. The most-watched video was watched 6,873,891 times, whereas the least-watched video was watched 102,452 times. The average number of views was $711,051,41( \pm 1,167,321)$. The overall length of videos was $327.69 \pm 324.17 \mathrm{~s}$; other descriptive statistics are shown in Table 5. The mean DISCERN, JAMA, GQS, and modified DISCERN scores were $47.91( \pm 14.464), 2.22$ $( \pm 0.944), 2.69( \pm 1.35)$, and $2.49( \pm 1.1310)$, respectively. Of all video uploaders, 39 were physicians. In total, 15 videos were uploaded by medical websites, 10 by commercial websites, and 4 by patients. According to the DISCERN scoring, 13 videos were excellent, 20 were good, 11 were average, 16 were poor, and 8 were very poor.
Overall, 36 videos (52.9\%) conveyed data on non-surgical treatment options for hemorrhoids, and 23 videos (33.8\%) conveyed data on surgical treatment. In the remaining 9 videos (13.2\%), both surgical and non-surgical treatments were explained. In four videos, patients mentioned their experiences with hemorrhoid treatments.

According to the linear regression analysis, video length, daily clicks, VPI, and comments/year did not affect GQS, DISCERN, and JAMA scores ( $\mathrm{p}=0.054, \mathrm{p}=0.773, \mathrm{p}=0.308$, $\mathrm{p}=0606$ ). In addition, a negative correlation was noted between dislike numbers and DISCERN scores ( $\mathrm{p}=0.02)$. A positive correlation was found between GQS score and the

Table 4. Modified discern scoring system

Modified discern scoring system

Reliability of information ( 1 point for every "Yes," 0 points for "No")

1. Are the aims clear and achieved?

2. Are reliable sources of information used? (i.e., publication cited, speaker is board-certified general surgeon)

3. Is the information presented balanced and unbiased?

4. Are additional sources of information listed for patient reference?

5. Are areas of uncertainty mentioned?

From Gabarron et al. ${ }^{16}$

Table 5. Data of YouTube ${ }^{\mathrm{TM}}$ videos

\begin{tabular}{lll} 
& Mean \pm standard deviation & Minimum-maximum \\
\hline Video length (sec) & $327.69 \pm 324.17$ & $73-2353$ \\
View count & $711.051 .41 \pm 1.167 .321$ & $102.452-6.873 .891$ \\
Daily view count & $603.63 \pm 1240.2$ & $39.20-7235$ \\
Like & $3022.57 \pm 4903.5$ & $82-33000$ \\
Dislike & $331.07 \pm 468.6$ & $9-2700$ \\
Comments/year & $112.46 \pm 200.4$ & $0-836$ \\
VPI & $87.66 \pm 8.5$ & $50-99.1$ \\
DISCERN & $47.91 \pm 14,464$ & $20-72$ \\
JAMA & $2.22 \pm 0.944$ & $0-3$ \\
GQS & $2.69 \pm 1.35$ & $1-5$ \\
Modified DISCERN & $2.49 \pm 1.310$ & $1-4$
\end{tabular}

Table 6. Correlation between quality scores

$\begin{array}{lllll} & \text { DISCORN } & \text { JAWA } & \text { GQS } & \text { Modified DISCORN } \\ \text { DISCORN } & 1 & 0.862 & 0.825 & 0.859 \\ \text { JAMA } & 0.862 & 1 & 0.781 & 0.830 \\ \text { GQS } & 0.825 & 0.781 & 1 & 0.760 \\ \text { Modified DISCERN } & 0.859 & 0.830 & 0.760 & 1\end{array}$

GQS: Global quality score 
number of clicks ( $\mathrm{p}=0.011$ ). Although there was a negative correlation between the modified DISCERN scores and the number of dislikes $(\mathrm{p}=0.007)$, there was a positive correlation between this score and the click counts ( $\mathrm{p}=0.016)$.

Seven parameter groups were examined using homogeneity one-way ANOVA and non-homogeneity Mann-Whitney U test. The results revealed a difference $(\mathrm{p}<0.001)$ in the video quality (DISCERN, JAMA, GQB, and modified DISCERN scores) among the uploaders.

No difference was observed between the number of views, viewing lengths, daily views, VPI, comment/year, and upload date. According to the groups, all quality values were better in the videos uploaded by the physicians. The groups with more than 200 views/day had statistically better QBS (Table 7).

\section{Discussion}

In this study, we examined the quality of videos on hemorrhoids on a large media platform accessed by patients.
We found that information completeness and reliability were weak, and the information was variable in terms of source and content. However, we found that the quality of videos made by the physicians and watched the most was statistically significantly better. This study aimed to evaluate the information on YouTube ${ }^{\mathrm{TM}}$ from the patients' perspective. Therefore, in our study, we used the keyword "hemorrhoids" as it is a more general disease term.

Our study is not the first study evaluating YouTube ${ }^{\mathrm{TM}}$ video quality. ${ }^{8,16,17,18,19}$ However, this is the first study to evaluate videos regarding hemorrhoids that are available to patients objectively. A recent study concluded that almost half of YouTube $^{\mathrm{TM}}$ videos about hemorrhoids are misleading or contain information. Although the results of this study and our study were similar, the previous study did not use JAMA, DISCERN, and GQS scores in the evaluation. ${ }^{20}$ For this reason, we believe that our study is the first study on this subject.

Table 7. Relationship between seven categorical variables and video quality

\begin{tabular}{|c|c|c|c|c|c|c|c|c|c|}
\hline & $\mathbf{n}$ & DISCERN & $\mathrm{p}$ & JAMA & $\mathrm{p}$ & GQS & $\mathrm{p}$ & $\begin{array}{l}\text { Modified } \\
\text { DISCERN }\end{array}$ & $\mathrm{p}$ \\
\hline \multicolumn{10}{|l|}{ Video source } \\
\hline Physicians & 39 & $57.77 \pm 9,077$ & $<0.001^{*}$ & $2.82 \pm 0.556$ & $<0.001^{*}$ & $3.49 \pm 1.023$ & $<0.001^{*}$ & $3.38 \pm 0.935$ & $<0.001^{*}$ \\
\hline Non-physicians & 29 & $33.59 \pm 8.87$ & & $1.41 \pm 0.7330$ & & $1.62 \pm 0.942$ & & $1.28 \pm 0.528$ & \\
\hline Old videos ( $>5$ years) & 26 & $44.65 \pm 14.4$ & 0.228 & $1.96 \pm 1.038$ & 0.075 & $2.46 \pm 1.392$ & 0.274 & $2.19 \pm 1.26$ & 0.148 \\
\hline New videos ( $\leq 5$ years) & 42 & $49.19 \pm 15.25$ & & $2.38 \pm 0.854$ & & $2.83 \pm 1.324$ & & $2.67 \pm 1.319$ & \\
\hline View count (first 34) & 34 & $45.71 \pm 14.43$ & 0.34 & $2.12 \pm 1.06$ & 0.372 & $2.82 \pm 1.507$ & 0.424 & $2.26 \pm 1.23$ & 0.167 \\
\hline View count (second 34) & 34 & $49.21 \pm 15,544$ & & $2.32 \pm 0.806$ & & $2.56 \pm 1.186$ & & $2.71 \pm 1.360$ & \\
\hline Daily view count (>200) & 33 & $47.61 \pm 15.42$ & 0.937 & $2.18 \pm 1.04$ & 0.745 & $3.12 \pm 1.38$ & $0.010 *$ & $2.45 \pm 1.25$ & 0.853 \\
\hline Daily view count $(\leq 200)$ & 35 & 47.3114 .79 & & $2.26 \pm 0.85$ & & $2.29 \pm 1.202$ & & $2.51 \pm 1.314$ & \\
\hline Video length ( $>5 \mathrm{~min}$ ) & 26 & $47.69 \pm 15.49$ & 0.919 & $2.01 \pm 1.1$ & 0.213 & $2.65 \pm 1.49$ & 0.859 & $2.54 \pm 1.44$ & 0.795 \\
\hline Video length ( $\leq 5 \mathrm{~min}$ ) & 42 & $47.31 \pm 14,863$ & & $2.33 \pm 0.816$ & & $2.71 \pm 1.27$ & & $2.45 \pm 1.23$ & \\
\hline VPI (>95) & 33 & $48.09 \pm 16.32$ & 0.737 & $2.21 \pm 0.893$ & 0.943 & $2.70 \pm 1.334$ & 0.973 & $2.52 \pm 1.326$ & 0.857 \\
\hline VPI $(\leq 95)$ & 35 & $46.86 \pm 13.83$ & & $2.23 \pm 1.003$ & & $2.69 \pm 1.352$ & & $2.46 \pm 1.314$ & \\
\hline Comments/year (>50) & 27 & $44.37 \pm 14,716$ & 0.17 & $2.04 \pm 1.091$ & 0.195 & $2.75 \pm 1.34$ & 0.672 & $2.30 \pm 1.295$ & 0.338 \\
\hline Comments/year $(\leq 50)$ & 41 & $49.49 \pm 15,004$ & & $2.34 \pm 0.825$ & & $2.63 \pm 1.37$ & & $2.61 \pm 1.321$ & \\
\hline
\end{tabular}


Although the DISCERN and JAMA tools are not designed to evaluate videos such as YouTube ${ }^{\mathrm{TM}}$ videos $^{21}$, they have been used in most studies and have been used to frequently emphasize low video quality. ${ }^{22,23}$ The study by Aydin and $\mathrm{Akyol}^{24}$ evaluated the quality of information regarding thyroid cancer in YouTube ${ }^{\mathrm{TM}}$ videos using the DISCERN and JAMA scores as well as the calculated video strength index.

In our study, JAMA, modified DISCERN, GQS, and DISCERN scores were low. This implied that YouTube ${ }^{\mathrm{TM}}$ videos on hemorrhoids lacked accurate and reliable information. Poor quality information accessed through YouTube $^{\mathrm{TM}}$ videos can provide inaccurate information and compel patients to make wrong decisions. It can also cause conflicts in the patient-physician relationship. ${ }^{25,26}$ In a previous study, only $58 \%$ of the uploaded videos regarding kidney stones were deemed useful using criteria similar to those we used. ${ }^{27}$ During the influenza A epidemic, $61 \%$ of the videos had useful information about the disease. ${ }^{28}$ Information on hemorrhoids on YouTube ${ }^{\mathrm{TM}}$ may not be of perfect quality, but it is important to raise awareness about clinical characteristics, and it may become more beneficial with increasing treatment options and information provided by the physician.

Except for a few studies, about $50 \%$ of video uploaders were physicians. In line with this, we found that YouTube videos produced by physicians were of high quality. Recently, similar findings were noted for videos concerning erectile dysfunction. ${ }^{18}$ Batar $^{29}$ showed that $74.6 \%$ of the videos uploaded on YouTube ${ }^{\mathrm{TM}}$ were from patients, $21.3 \%$ from physicians, $1 \%$ from dieticians, and $3.1 \%$ from advertisement agencies. In our study, the DISCERN, JAMA, GQS, and modified DISCERN scores for the physician videos were high, and the scores for videos by non-physicians were considerably low and were similar to those reported previously. ${ }^{29}$

In our study, there were no significant differences between the video quality (except who uploaded the video) and the seven variables (old or new, high or low views, daily views, video length, popularity, and comments/year). We found that GQS scores of videos viewed more than 200 times a day were significantly higher $(\mathrm{p}=0.01)$. Notably, there are studies reporting that poor quality videos are more popular than good quality videos. ${ }^{30,31}$ In our study, a negative correlation was noted between dislike numbers and DISCERN scores. Moreover, a positive correlation was observed between GQS scores and the number of clicks. We found a negative correlation between the modified DISCERN scores and the number of dislikes but a positive correlation between this score and click counts.
A recently published article reported a negative association between JAMA and DISCERN scores and high popularity bariatric surgery videos reviews on YouTube ${ }^{\mathrm{TM}} .{ }^{15}$ In our study, no significant difference was found between the quality scores of popular videos and unpopular videos. Contrary to the literature, this situation was evaluated as the more frequent hemorrhoidal disease occurrence and the more accessible information on the subject. Nevertheless, it should be noted that in our study, the information provided by the physicians was of higher quality.

Published studies support our result that the quality of videos uploaded by physicians is higher than of those uploaded by non-physicians. However, it has been stated that viewing rates of certain videos may be lower because their contents are difficult for patients to understand. ${ }^{31,32}$

\section{Study Limitations}

Our study has certain limitations. As there is limited English content on YouTube ${ }^{\mathrm{TM}}$, we did not study videos on health information websites other than YouTube ${ }^{\mathrm{TM}}$. The videos were analyzed by doctors with evidence-based knowledge of hemorrhoids instead of the general public, who would watch and learn from these videos. It would have been useful to obtain public opinion on this matter. Irrespective, the study has certain strengths. This is the first objective study on such a popular and common health problem in the literature, and the number of videos watched and evaluated was high.

\section{Conclusion}

The quality of information about hemorrhoids on YouTube ${ }^{\mathrm{TM}}$ is variable. We noted no difference in terms of viewing and popularity of useful and misleading videos. Physicians who upload videos should take this job more seriously and create better quality videos considering the target audience. In addition, it is more appropriate for patients to prefer these videos as a source of information. These findings indicate that physicians should advise their patients on the poor quality of information on YouTube ${ }^{\mathrm{TM}}$ when using this platform as a source of information on hemorrhoids.

\section{Ethics}

Ethics Committee Approval: Ethics committee approval was not required in this study.

Peer-review: Externally and internally peer reviewed.

\section{Authorship Contributions}

Surgical and Medical Practices: V.B.T., Concept: V.B.T., Design: V.B.T., Data Collection or Processing: A.Ü., Analysis or Interpretation: V.B.T., Literature Search: A.Ü., Writing: V.B.T. 


\section{Conflict of Interest: No conflict of interest was declared by the authors. \\ Financial Disclosure: The authors declared that this study received no financial support.}

\section{References}

1. Internet World Stats. Internet Users Distrubition in the World-2021. Available from: www.internetworldstats.com/stats.htm.

2. Radonjic A, Hing NNF, Harlock J, Naji F. YouTube as a source of patient information for abdominal aortic aneurysms. J Vasc Surg 2020;71:637644.

3. Lohsiriwat V. Treatment of hemorrhoids: a coloproctologist's view. World J Gastroenterol 2015;21:9245-9252.

4. Riss S, Weiser FA, Schwameis K, Riss T, Mittlböck M, Steiner G, Stift A. The prevalence of hemorrhoids in adults. Int J Colorectal Dis 2012;27:215220.

5. Google Trends [Available from: www.trends.google.com/trends/ explore?date=all_2008\&gprop=youtube\&q=hemorrhoids.

6. Yoo JH, Kim J. Obesity in the new media: a content analysis of obesity videos on YouTube. Health Commun 2012;27:86-97.

7. Sahin AN, Sahin AS, Schwenter F, Sebajang H. YouTube videos as a source of information on colorectal cancer: What do our patients learn? J Cancer Educ 2019;34:1160-1166.

8. Gokcen HB, Gumussuyu G. A quality analysis of disc herniation videos on YouTube. World Neurosurg 2019:S1878-8750(19)30246-3. doi: 10.1016/j.wneu.2019.01.146. Epub ahead of print.

9. ReFaey K, Tripathi S, Yoon JW, Justice J, Kerezoudis P, Parney IF, Bendok BR, Chaichana KL, Quiñones-Hinojosa A. The reliability of YouTube videos in patients education for glioblastoma treatment. J Clin Neurosci 2018;55:1-4

10. MacLeod MG, Hoppe DJ, Simunovic N, Bhandari M, Philippon MJ, Ayeni OR. YouTube as an information source for femoroacetabular impingement: a systematic review of video content. Arthroscopy 2015;31:136-142.

11. Cassidy JT, Fitzgerald E, Cassidy ES, Cleary M, Byrne DP, Devitt BM, Baker JF. YouTube provides poor information regarding anterior cruciate ligament injury and reconstruction. Knee Surg Sports Traumatol Arthrosc 2018;26:840-845.

12. Kuru T, Erken HY. Evaluation of the quality and reliability of YouTube videos on rotator cuff tears. Cureus 2020;12:e6852.

13. Batar N, Kermen S, Sevdin S, Yıldız N, Güçlü D. Assessment of the quality and reliability of information on nutrition after bariatric surgery on YouTube. Obes Surg 2020;30:4905-4910.

14. Singh AG, Singh S, Singh PP. YouTube for information on rheumatoid arthritis—a wakeup call? J Rheumatol 2012;39:899-903.

15. Ferhatoglu MF, Kartal A, Ekici U, Gurkan A. Evaluation of the reliability, utility, and quality of the information in sleeve gastrectomy videos shared on open access video sharing platform YouTube. Obes Surg 2019;29:14771484.

16. Gabarron E, Fernandez-Luque L, Armayones M, Lau AY. Identifying measures used for assessing quality of YouTube videos with patient health information: a review of current literature. Interact J Med Res 2013;2:e6.
17. Pant S, Deshmukh A, Murugiah K, Kumar G, Sachdeva R, Mehta JL. Assessing the credibility of the "YouTube approach" to health information on acute myocardial infarction. Clin Cardiol 2012;35:281-285.

18. Fode M, Nolsøe AB, Jacobsen FM, Russo GI, Østergren PB, Jensen CFS, Albersen M, Capogrosso P, Sønksen J; EAU YAU Men's Health Working Group. Quality of information in YouTube videos on erectile dysfunction. Sex Med 2020;8:408-413.

19. Zhang S, Fukunaga T, Oka S, Orita H, Kaji S, Yube Y, Yamauchi S, Kohira $\mathrm{Y}$, Egawa H. Concerns of quality, utility, and reliability of laparoscopic gastrectomy for gastric cancer in public video sharing platform. Ann Transl Med 2020;8:196.

20. Sturiale A, Dowais R, Porzio FC, Brusciano L, Gallo G, Morganti R, Naldini G. Youtube as a source of patients' and specialists' information on hemorrhoids and hemorrhoid surgery. Rev Recent Clin Trials 2020;15:219226.

21. Azer SA. Are DISCERN and JAMA suitable instruments for assessing youtube videos on thyroid cancer? methodological concerns. J Cancer Educ 2020;35:1267-1277.

22. Eksi Ozsoy H. Evaluation of YouTube videos about smile design using the DISCERN tool and Journal of the American Medical Association benchmarks. J Prosthet Dent 2021;125:151-154.

23. Szmuda T, Syed MT, Singh A, Ali S, Özdemir C, Sloniewski P. YouTube as a source of patient information for Coronavirus Disease (COVID-19): a content-quality and audience engagement analysis. Rev Med Virol 2020;30:e2132.

24. Aydin MA, Akyol H. Quality of information available on YouTube videos pertaining to thyroid cancer. J Cancer Educ 2020;35:599-605.

25. Berland GK, Elliott MN, Morales LS, Algazy JI, Kravitz RL, Broder MS, Kanouse DE, Muñoz JA, Puyol JA, Lara M, Watkins KE, Yang H, McGlynn EA. Health information on the Internet: accessibility, quality, and readability in English and Spanish. JAMA 2001;285:2612-2621.

26. Bao H, Zhu F, Wang F, Liu Z, Bao MH, He S, Zhu Z, Qiu Y. Scoliosis related information on the internet in China: can patients benefit from this information? PLoS One. 2015;10:e0118289. doi: 10.1371/journal. pone.0118289.

27. Sood A, Sarangi S, Pandey A, Murugiah K. YouTube as a source of information on kidney stone disease. Urology 2011;77:558-562.

28. Pandey A, Patni N, Singh M, Sood A, Singh G. YouTube as a source of information on the HlNl influenza pandemic. Am J Prev Med 2010;38:ele3. doi: 10.1016/j.amepre.2009.11.007.

29. Kumar N, Pandey A, Venkatraman A, Garg N. Are video sharing web sites a useful source of information on hypertension? J Am Soc Hypertens 2014:8:481-490.

30. Tartaglione JP, Rosenbaum AJ, Abousayed M, Hushmendy SF, DiPreta JA. Evaluating the quality, accuracy, and readability of online resources pertaining to hallux valgus. Foot Ankle Spec 2016;9:17-23.

31. Yaradılmış YU, Evren AT, Okkaoğlu MC, Öztürk Ö, Haberal B, Özdemir M. Evaluation of quality and reliability of YouTube videos on spondylolisthesis. Interdiscip Neurosurg 2020;22:100827.

32. Desai T, Shariff A, Dhingra V, Minhas D, Eure M, Kats M. Is content really king? An objective analysis of the public's response to medical videos on YouTube. PLoS One 2013;8:e82469. 